\title{
TATAR CULTURE-SPECIFIC WORDS OF THE SEMANTIC FIELD 'ANIMALS' RELATIVE TO ENGLISH
}

Gulnara Mohtarovna Nurtdinova

Kazan Federal University, Kazan, Russia

Dilyara Marsovna Sadykova

Kazan Federal University, Kazan, Russia

E-mail: gnurtdinova@bk.ru

Recepción: 05/08/2019 Aceptación: 16/09/2019 Publicación: 23/10/2019

\section{Citación sugerida:}

Nurtdinova, G.M. y Sadykova, D.M. (2019). Tatar culture-specific words of the semantic field 'animals' relative to English. 3C TIC. Cuadernos de desarrollo aplicados a las TIC. Edición Especial, Octubre 2019, 246-257. doi: https://doi.org/10.17993/3ctic.2019.83-2.246-257

Suggested citation:

Nurtdinova, G.M. \& Sadykova, D.M. (2019). Tatar culture-specific words of the semantic field 'animals' relative to English. 3C TIC. Cuadernos de desarrollo aplicados a las TIC. Special Issue, October 2019, 246-257. doi: https://doi.org/10.17993/3ctic.2019.83-2.246-257 


\section{ABSTRACT}

The article is dealing with the problem of semantic gaps, the part of which is a group of culture-specific words. The authors tried to systemize the research by distributing such words into different semantic fields. While comparing the fields on the example of a pair of languages anyone can see the difference in conceptualization of the world picture which is verbalized by the language. The authors researched the Tatar specific concepts relative to English in the field 'Animals'. The results showed that the difference is not so big, and it is proved by the quantity of semantic distance coefficient. It is 6.5 , while the other semantic fields present bigger difference: it is 8.44 for the field 'family', 8.2 for the field 'household objects', 9.93 for the field 'Food' and 11.7 for the field 'Measures'. So far, the biggest difference is in the fields of Religion and Measures. The difference between the Tatar and English fields 'Animals' can be explained by the fact that Tatars were nomads in the past and such an animal like a horse (among 14 words 11 of them are denoting a house age and color that is not presented in English) was important for them. One more argument is the number of Tatar proverbs about a horse. We have found 757 proverbs in the dictionary of Tatar proverbs and sayings.

\section{KEYWORDS}

Language, Linguistics, Semantics, Vocabulary, Lexical Gaps, Semantic Field, Culture-Specific Concepts. 


\section{INTRODUCTION}

The linguists whose names are well known such as Chomsky, Lehrer, Nida and others published a lot of works dedicated to the notion 'non-equivalence'. They believe that such words exist because of difference in culture and denote the objects or phenomena unknown to the people of other culture. One of them, Nida (1964), the founder of the theory of formal and dynamic equivalence supposed that several among civilizations maybe reason difficulties in order that the interpreter. His words are showing that the differences between cultures relate to a culture world picture, which is verbalized by a language and it is proved by Russian researcher S. Ter-minasova. Each language preserves itself over time and represents it to future generations, in his opinion, each language represents the worldview of national culture (Ter-minasova, 2000). Moreover, it is very important to learn a native language to preserve ethnical identity (Babenko, 2015). The differences between cultures are presented in the language in grammar structures, stylistic devices, lexicology and other language levels but we are dealing with lexicology. Non-equivalent words exist in any language presenting the differences between cultures because they present the notions existing in one culture and that are absent in another one. Muscovite scholars Vereshshagin and Kostomarov (1990) supposed which such vocabularies can have the equipollent into tongue A however they cannot have it in the tongue $\mathrm{B}$ (Cvilikaite, 2006). The reasons of existing non-equivalent words have been still researched. As it has been mentioned above, the culture of some ethnic group cannot have the objects or phenomena that are not presented in the culture of other people, so the language does not have the word. For instance, Sabantui is the celebration of Tatar people and the English language does not have the word for it as the English do not have such a holiday. In Tatar there is no word for Easter as Tatars' religion is Islam and there is no such holy celebration. Translation of such words is not difficult because there are some translation technics such as transliteration, transcription and others. But the technics do not present the meaning of the word, so a translator presents the explanation in the footnotes or in the comments. One rather proof of the existing gaps can be described via 
the verity that some objects or phenomena exist in both cultures, but they are not important for one culture and the language does not have the word whereas the object or phenomena exist. For example, the Tatar word kodagy in English has the following meanings: The mother-in-law and the mother-in-law of the bride and groom's parents, grand-sisters, or married relatives do not have the right English equivalence.in English there is no exact equivalent for the mother of the wife or the mother of the husband for the parents of the bride and groom and their relatives Certainly English people have such relatives but the English language does not have the word. It is proved by the results of the research made by one of the authors (Nutrtdinova, 2015), which show that family hierarchy is broader in Tatar culture. For words that cannot easily be equated well, linguists are looking for the right words, and for now, vocabulary gaps, extraneous words, untranslatable words, non-existent words, and so on (Janssen, 2012; Sankaravelayuthan \& Vishwa Vidyapeetha, n.d.). We are dealing with Tatar specific culture notions that are a part of non- equivalent words relative their lacunas in English, namely we are presenting the results of the research in the semantic field 'Animals'. Earlier we researched the groups 'Family and human being environment', 'Religion', 'Food', 'Measures' and 'Household objects'.

\section{METHODOLOGY}

Our study is aimed at the analysis of a semantic field 'Animals'. The words of the field have been selected from Tatar fairy tales published in Tatar. Researchers at the Verona Academy have devised a method that we use. We use equivalence indices in the dictionary of either the target language or the word created by a free word combination in English (Fenenko, 2013). We have studied Tatar, English, electronic dictionaries, and English explanatory dictionaries. In fact, our main obstacle is that the dictionary is not comprehensive and reflects the specific Tataric culture concepts. Finding out that in learning Tataric culture, Englishmen have no reason to misunderstand it and leading to conflicts as the marker of the category ailng/friend (Kalegina et al., 2015). Russian linguist Titov (2002) proposed the method, which allows turning up the difference of the world 
picture conceptualization. In his opinion, when we find a direct equivalent in an explanatory article of a dictionary that yields similar concepts for a word, we must find that both languages determine the semantic context in a similar way. However, in the case when we need a few words to explain the word meaning we can say that the pair language does not have an analogous concept. We also use his formula to calculate the semantic distance coefficient (SDC) showing the difference between semantic fields. SDC $=\mathrm{D}: \mathrm{Q}, \mathrm{D}$ is the summation of every the paroles of the descriptions in the semantic field and $Q$ is the numeral of every the descriptions into the semantic field (Titov, 2002).

\section{RESULTS AND DISCUSSION}

Words that are not present in the vocabulary indicate signs of a slit or a gap that some linguists distinguish between these slots as a random order (Vlachov \& Florin, 1986). Words that do not exist but can be expected to appear seemingly ordinary to be termed random slots, but random slots can be defined as lexical slots and can be realized in a semantic sentence at different levels (Sankaravelayuthan \& Vishwa Vidyapeetha, n.d.). In the opinion of Russian linguist Fenenko (2013) the first step while conducting the research of semantic gaps is to select the words that do not have straightforward equivalents in another language. However, we should exclude proper names. Also, it is necessary at the first stage to choose nouns only as usually specific culture words are expressed per nouns and rarely by adjectives derived from the nouns (Vlachov \& Florin, 1986). It is obvious that it is easier to work with the dictionaries but in the case of the Tatar language (the official language of the Republic of Tatarstan - one of the regions of Russia) we still have a small number of English-Tatar dictionaries and they frequently do not contain non-equivalent words.

The question is what can be referred to semantic gaps. Russian researcher Barchudarov (1975) distributed them in the following groups: proper names, specific culture words and occasional lacunas. We are dealing with specific culture words. One of the ways to solve the problem how to present their meaning is to 
make an Explanatory dictionary of Tatar specific concepts that can be used in developing machine translation process for the language pair Tatar - English. In the opinion of Linguist Rajendran Sankaravelayuthan "A dictionary in such cases provides a mere explanation of the concept encoded by a source language. Unfortunately, such meaning explanations usually are not good in natural language use" (Sankaravelayuthan \& Vishwa Vidyapeetha, n.d.). Because of above mentioned reasons and being Tatar native speakers who speak English we have selected Tatar specific culture concepts from Tatar fairy tales published in Tatar. The choice is diseased per the reality than the fictions were told by residents of Tatar villages who spoke natural language and later the tales were published with comments of the researchers. We have distributed specific-culture words in a few semantic fields, one of them is 'Animals'. Fenenko (2013) believes that while comparing smaller fields anyone can easily see the difference in conceptualization of word picture verbalized by the language.

In this essay, we attempt to provide a draft of an English explanatory passage for the semantic context of Tataric. The string is small, 14 word only while the field for kinship has 42 words, the field for food has 16 words, the field for religion has 25 words, the field for measures has 16 words and the field household objects has 44 words. We think that because of climate conditions English and Tatar people have the same animals but there is some difference due to different historical conditions. English people live on the island and have a settled way of life. Tatar people were nomads and lived mostly in prairies and woodlands, so a horse was very important for them in the past. Among 14 words referring to the field 'animal' found by us in Tatar fairy tales 11 words denoted horses of different ages (taj, kolyn, kolkai, baytal) and colors (kyzgylt, akbuz, zhiran), etc. It is also proved by the fact that in the dictionary of Tatar proverbs (3 volumes) we have found 757 proverbs dedicated to a horse. 
In fact, we bring up an explanatory dictionary draft, and finally provide the necessary word modifications to explain the meaning of the word. As it has been mentioned above, in the case we need a few words to explain the word meaning we may tell than the mate tongue does not have a similar sense. The rather mots we demand the imperial is the interval amid the senses.

\section{Animals}

Kyzgylt - adj. (the color of a horse coat) chestnut, red and shot with pink 13.

Yelky - n. a herd horse breeding specially for meal 9.

Kashka - n. (for an animal) horse with a blaze 8 .

Taj - n. a foal up to three years old 8 . Kolyn - n. a foal up to one year old 8.

Kyrykmysh taj - a foal from one to two years old 8 .
Argamak - n. Central Asian breed of saddle horse 7 .

Zhanvar - n. predatory animals, beasts of prey 6 .

Akbuz - adj. white and grey color 5 .

Kolkai - n. a yearling foal 5.

Kiek - n. fowl, game, game animals 5.

Baytal - n. barren mare 3 .

Zhiran - adj. chestnut, red 3.

Zhanlek $-\mathrm{n}$. wild animals 3 .

Table 1. Semantic Distance Coefficient (SDC) for Semantic Field Animals.

\begin{tabular}{|c|c|c|}
\hline $\begin{array}{c}\text { Number of Explanatory } \\
\text { Words }\end{array}$ & $\begin{array}{c}\text { Number of specific culture } \\
\text { words }\end{array}$ & Total number of words \\
\hline 3 & 3 & 9 \\
\hline 5 & 3 & 15 \\
\hline 6 & 1 & 6 \\
\hline 7 & 1 & 7 \\
\hline 8 & 4 & 32 \\
\hline 9 & 1 & 9 \\
\hline 13 & 1 & 13 \\
\hline & $\mathbf{Q = 1 4}$ & $\mathbf{D = 9 1}$ \\
\hline & & SDC= D/Q=90/14=6.5 \\
\hline
\end{tabular}


In the first column we presented the numeral of the mots we demand against illustrate the purpose. The second column shows how many words we have selected with the same number of words to explain the meaning. We found 3 words that need 3 words to describe the meaning, 3 words that need 5 words, 1 word that need 6 words, etc. The third column shows the total number of words, which we are getting by multiplying the figures of the first and the second columns.

We used the formula SDC =D/Q proposed by Titov (Kalegina et al., 2015) (where $\mathrm{D}$ is a total number of words and $\mathrm{Q}$ is a number of specific culture words) to calculate the semantic distance coefficient, which is 6.5. In average we need 6.5 words to explain the meaning of the words for the field 'Animals'.

\section{SUMMARY}

We suppose that the most confusing fact for English people is the one that Tatars breed horses for eating (Yelky) which is natural for people who were nomads in the past. Also it should be taken into consideration that the colors and ages of horses in Tatar are also different from English. Three words that do not have the straightforward equivalents are denoting wild animals: zhanvar, kiek, zhanlek. In Tatar there are special words to single out wild animals which are presented in English by a few words. So SDC for the field Animals is 6.5 as opposed to 8.2 for the field Household objects, 8.44 for the field Family, 12.44 for the field Religion, 9.93 for Food, 11.7 for the field Measures.

\section{CONCLUSION}

The semantic gap has created profound problems for linguists that have led to various definitions and names, as discussed above: lexical gaps, non-lexical words, untranslatable words, non-existent words, and so on. The problem is not easy to solve as the gaps can exist in language A relative to the language $\mathrm{B}$, but they are not presented relative to the language $\mathrm{C}$. It is obvious that it is necessary 
to research them by studying a pair of specific languages. Many researchers tried to systemize the methods and one of the most effective methods is the method of semantic fields. While comparing the fields anyone can easily see the difference in conceptualization of the word picture which is verbalized by the language. Moreover, the method helps to simplify the process of making an expositive glossary of specific civilization meanings besides supports the development of machine translation. What is more important research results can show the difference in culture world picture and prevent conflicts into the proceeding of Intercultural relevance.

\section{ACKNOWLEDGEMENTS}

The work is performed according to the Russian Government Program of Competitive Growth of Kazan Federal University.

\section{REFERENCES}

Babenko, O. V. (2015). Language as a basic feature of ethnos uniting within the conditions of modern challenges. Fournal of Language and Literature, 6(3), 168170. doi: https://doi.org/10.7813/j11.2015/6-3/38

Barchudarov, L. G. (1975). Language and Translation. Moscow: Mezdunarodnye Otnosheniya.

Chomsky, N. (1965). Aspects of the Theory of Syntax. Cambridge: The MIT Press.

Gvilikaite, J. (2006). Lexical Gaps. Retrieved from http://donelaitis.vdu.lt/ publikacijos/dd45_cvilikaite.pdf

Fenenko, N. A. (2013). French Realias in the Aspect of the Theory Iof Renomination. Voronezh, Russia: Izdatelstvo Voronezhskogo Universiteta.

Janssen, M. (2012). Lexical gaps. Retrieved from http://maarten.janssenweb. net/Papers/2012-lg-janssen.pdf 
Kalegina, T. E., Takhtarova, S. S., \& Zaglyadkina, T. Y. (2015). Denglish and Franglais in the framework of the modern European linguistic landscape. Journal of Language and Literature, 6(3), 195-198. Retrieved from http://dspace.kpfu.ru/xmlui/bitstream/handle/ net/142405/SCOPUS 20780303 - 2015 -6-3-SID 84959051476 -a 1. pdf;jsessionid=E97E1A2175E20B5E97CF759667A96BFB? sequence $=-1$

Nida, E. (1964). Toward A Science of Translating. Leiden: E. J. Brill.

Nutrtdinova, G. (2015). Fournal of Sustainable Development, 4, 169-176.

Sankaravelayuthan, R., \& Vishwa Vidyapeetha, A. (n.d.). Lexical gaps in the vocabulary structure of a language. Retrieved from https://www.researchgate.net/ publication/330141511_Lexical_gaps_in_the_vocabulary_structure_of_a_ language

Ter-minasova, S. (2000). Language and Intercultural Communication. Moscow: Slovo.

Titov, V. (2002). General Quantitative Lexicology of Romanic Languages. Voronezh. Russia: Izdatelstvo Voronezhskogo Universiteta.

Vereshshagin, E. M., \& Kostomarov, V. G. (1990). The Language and the Culture. Moscow.

Vlachov, S., \& Florin, S. (1986). Lexical Gaps in Translation. Moscow, Russia: Vysshaya Shkola. 
Edición Especial Special Issue Octubre 2019 DOI: https://doi.org/10.17993/3ctic.2019.83-2.246-257 